Authors have nothing to disclose with regard to commercial support.

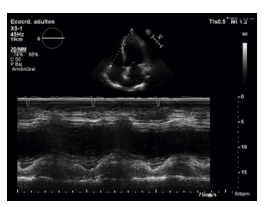

\section{TRICUSPID ANNULAR \\ PLANE SYSTOLIC \\ EXCURSION: THE \\ WELCOME PARAMETER \\ To the Editor:}

We read with great interest the article recently published in the Journal by García Gigorro and colleagues ${ }^{1}$ about the evaluation of right ventricular function (RVF) after cardiac surgery. In this article, they concluded that tricuspid annular plane systolic excursion (TAPSE) is a robust measure of RVF. In our opinion, however, several questions about this matter still remain in the air.

As previous studies have shown, after cardiac surgery TAPSE is reduced in the context of otherwise normal overall RVF. Our first question, therefore, is this: which is the normal TAPSE value that we should consider in this context? Still another question unsolved is this: are there differences between off-pump and on-pump coronary artery bypass grafting? ${ }^{2}$

Otherwise, the evaluation of RVF is essential not only for the correct hemodynamic management of critically ill and cardiac surgical patients but also for those patients with severe tricuspid regurgitation (TR), especially if surgical treatment is contemplated. Diagnostic criteria for surgical timing in cases of TR associated with left-sides valvulopathy are well known and perfectly defined by the scientific societies; however, surgical timing in cases of isolated TR is less well established. ${ }^{3}$ TAPSE is an easily measured parameter that can define RVF (Figure 1). A recent article by Sun and coworkers analyzed TAPSE values that could predict mortality and morbidity in patients who underwent isolated tricuspid valve surgery. ${ }^{4}$ Although it is a small study with few patients, it highlights the need for further prospective trials to define better the RVF cutoff values for surgery in cases of TR. TAPSE is a noninvasive and easily measured echocardiographic parameter that, in view of these 2 research studies, could, together with other clinical factors, be extremely useful before tricuspid valve surgery to improve its diagnostic approach, prognosis, and selection of surgical timing.

\footnotetext{
The Editor welcomes submissions for possible publication in the Letters to the Editor section that consist of commentary on an article published in the Journal or other relevant issues. Authors should: • Include no more than 500 words of text, three authors, and five references. $\bullet$ Type with double-spacing. • See http://jtcs.ctsnetjournals.org/ misc/ifora.shtml for detailed submission instructions. • Submit the letter electronically via jtcvs.editorialmanager.com. Letters commenting on an article published in the JTCVS will be considered if they are received within 6 weeks of the time the article was published. Authors of the article being commented on will be given an opportunity of offer a timely response ( 2 weeks) to the letter. Authors of letters will be notified that the letter has been received. Unpublished letters cannot be returned.
}

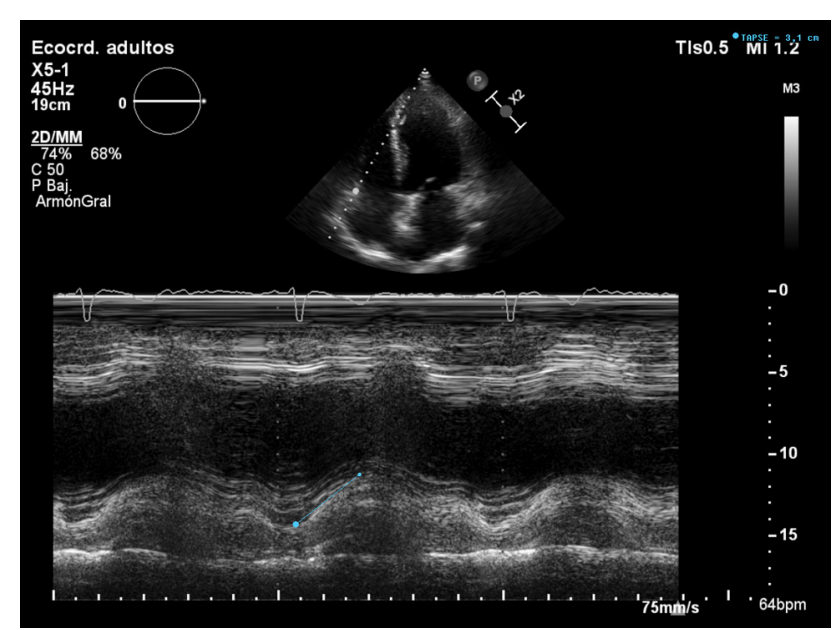

FIGURE 1. Tricuspid valve annular plane systolic excursion by M-mode echocardiography.

Ana Fidalgo, MD

María Martín, $M D, P h D$

Jesús M. De la Hera, MD, PhD

Cardiology Department

Hospital Universitario Central de Asturias

Oviedo, Asturias, Spain

\section{References}

1. Garcia Gigorro R, Renes Carreño E, Mayordomo S, Marín H, Perez Vela JL, Corres Peiretti MA, et al. Evaluation of right ventricular function after cardiac surgery: the importance of tricuspid annular plane systolic excursion and right ventricular ejection fraction. J Thorac Cardiovasc Surg. 2016;152:613-20.

2. Raina A, Vaidya A, Gertz ZM, Chambers S, Forfia PR. Marked changes in right ventricular contractile pattern after cardiothoracic surgery: implications for post-surgical assessment of right ventricular function. J Heart Lung Transplant. 2013;32:777-83.

3. Spanish Society of Cardiology Working Group on Clinical Practice Guidelines for the Treatment of Valvular; Group of Expert Reviewers for the Clinical Practice Guidelines for the Treatment of Valvular Heart Disease; Spanish Society of Cardiology Clinical Practice Guidelines CommitteeAlonso Gómez ÁM, Gómez de Diego JJ, Barba J, Barón G, Borrás X, Evangelista A, et al. Comments on the ESC guidelines on the management of valvular heart disease (version 2012). A report of the Task Force of the Clinical Practice Guidelines Committee of the Spanish Society of Cardiology. Rev Esp Cardiol (Engl Ed). 2013;66:85-9.

4. Sun X, Zhang H, Aike B, Yang S, Yang Z, Dong L, et al. Tricuspid annular plane systolic excursion (TAPSE) can predict the outcome of isolated tricuspid valve surgery in patients with previous cardiac surgery? J Thorac Dis. 2016;8:369-74.

\section{http://dx.doi.org/10.1016/j.jtcvs.2016.06.006}

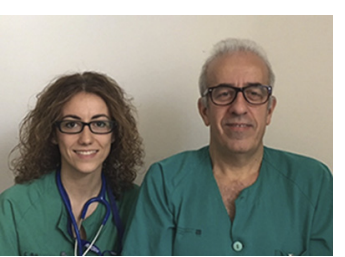

THE TRICUSPID

ANNULAR PLANE

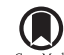

\section{SYSTOLIC EXCURSION}

\section{STRIKES BACK}

Reply to the Editor:

With great interest, we read the Letter to the Editor titled

"Tricuspid Annular Plane Systolic Excursion: The Welcome Parameter." In this letter, the authors comment on our article, ${ }^{1}$ and they ask about different aspects of the importance of tricuspid annular plane systolic excursion (TAPSE) after cardiac surgery. We thank the authors for 